\title{
Avaliação da aprendizagem e inclusão escolar: a singularidade a serviço da coletividade
}

\author{
Ana Maria de Lima Souza \\ Marasella del Cármen Silva Rodrigues Macedo
}

\begin{abstract}
Resumo
Pretende-se com este trabalho discutir a avaliação da aprendizagem escolar como meio de inclusão/exclusão a partir da análise de conceitos que permeiam as duas temáticas. Através de um estudo teórico são apresentados aspectos relevantes que possibilitam ou dificultam a consolidação do processo de avaliação para a diversidade, em torno das seguintes questões: Como analisar a inclusão se não a partir da reflexão sobre a sua lógica contrária, a exclusão? Como avaliar para a inclusão, considerando as diferenças, sem relativizá-las ou centrá-las apenas nas limitações físicas, intelectuais ou sociais? Foram adotadas, como referencial, teorias críticas na intenção de superar uma visão determinante acerca das características individuais, que compreendam os seres humanos inseridos em um contexto social, histórico e cultural amplo e repleto de contradições. Conclui-se que a escola deve preparar indivíduos capazes de avaliar suas ações, generalizar conhecimentos e experiências, fazer análises e sínteses, considerando não apenas a dimensão individual, mas, sobretudo, coletiva.
\end{abstract}

Palavras-chave: Avaliação, aprendizagem escolar, psicologia histórico-cultural.

\section{Learning assessment and school inclusion: uniqueness in the service of collectivity}

\begin{abstract}
In this paper we discuss the assessment of learning as a means of inclusion/exclusion through the analysis of concepts that permeate both themes. Through a theoretical study, we present relevant aspects which enable or hinder the consolidation of the evaluation process for diversity relating to the following issues: How to analyze inclusion if not from reflecting about its logical contrary: exclusion? How to evaluate inclusion by focusing only on physical, intellectual or social limitations? We adopted critical theories for reference in an attempt to overcome the vision of determining individual characteristics that include humans embedded in a social, historical and cultural context, which is broad and full of contradictions. We conclude that the school must prepare individuals able to evaluate their actions, generalizing knowledge and experience, making analysis and synthesis, considering not only the individual dimension, but above all, the collectivity.
\end{abstract}

Keywords: Evaluation, school learning, cultural-historic psychology.

\section{Evaluación del aprendizaje e inclusión escolar: la singularidad a servicio de la colectividad}

\section{Resumen}

La intención de este trabajo es discutir la evaluación del aprendizaje escolar como medio de inclusión/exclusión a partir del análisis de conceptos que permean ambas temáticas. A través de un estudio teórico se presentan aspectos relevantes que facilitan o dificultan la consolidación del proceso de evaluación para la diversidad y giran alrededor de las siguientes indagaciones: ¿Cómo analizar la inclusión a no ser a partir de la reflexión de su lógica contraria: la exclusión? ¿Cómo evaluar para la inclusión considerando las diferencias sin relativizarlas o centrarlas apenas en las limitaciones físicas, intelectuales o sociales? Como referencial se adoptaron teorías críticas con la intención de superar una visión determinante de las características individuales, referencias que comprendan los seres humanos como parte de un contexto social, histórico y cultural amplio y repleto de contradicciones. Se concluye que la escuela debe preparar individuos capaces de evaluar sus acciones, generalizar conocimientos y experiencias, hacer análisis y síntesis, llevando en cuenta no sólo la dimensión individual, sino principalmente la colectiva.

Palabras Clave: Evaluación, aprendizaje escolar, psicología histórico-cultural. 


\section{Introdução}

Este artigo pretende discutir, por meio de um estudo teórico, a avaliação da aprendizagem escolar como meio de inclusão/exclusão dos alunos com e sem deficiência na escola. O principal aporte para essa análise são as teorias críticas da Educação e da Psicologia, cujos princípios estão direcionados para a apropriação dos conhecimentos elaborados para a humanização de indivíduos singulares e sua inserção no mundo da cultura.

O reconhecimento da importância da avaliação na escola é peremptório para os envolvidos com o sistema de ensino, independentemente do lugar que ocupem.

A despeito de a avaliação configurar-se como um importante componente pedagógico, o que se observa é que o entendimento acerca das suas finalidades está vinculado aos procedimentos técnicos, o que resulta em uma fragmentação do processo avaliativo e na valorização da seleção, em detrimento da identificação das reais necessidades dos alunos.

As atenções dos pais, alunos, profissionais da educação e sistema de ensino estão voltadas para a retenção ou promoção de uma série de escolaridade para a posterior. Para o sistema, o interesse reside nos percentuais de aprovação e reprovação; os responsáveis por alunos estão preocupados com o avanço dos seus filhos nas etapas escolares; os professores a utilizam como mecanismo de controle de disciplina e como forma de corroborar a sua própria autoridade, por meio de ameaças; os alunos anseiam pela aprovação. Destarte, o ensino e a aprendizagem ficam relegados a uma pedagogia do exame (Luckesi, 2008).

A promoção voltada para as notas não distingue 0 que foi realmente apreendido pelos alunos, que habilidades foram desenvolvidas, que comportamentos foram efetivamente transformados e que valores foram construídos e solidificados; considerando que medir não é avaliar e sim adotar em uma escala de conceitos ou valores um ponto que caracterize e localize os estudantes apenas nas séries/anos nas quais deverão ser retidos ou promovidos.

Para Luckesi (2011) a avaliação é "uma atribuição de qualidade com base em dados relevantes da aprendizagem dos educandos, para uma tomada de decisão" (p. 264). Nesse sentido, a avaliação distancia-se do atual caráter puramente objetivo ao qual está relegado, devido ao valor que se tem atribuído às notas, para assumir uma condição mais subjetiva e vinculada à realidade da maneira como esta se apresenta. Dito de outro modo, as notas não traduzem a subjetividade que alunos e professores vivenciam cotidianamente, pois a realidade concreta da sociedade se enleia com os critérios objetivos impostos pelo exame.

A realidade escolar frequentemente representa o reflexo da sociedade com suas práticas e valores ideológicos. Destacam-se nesse contexto as práticas avaliativas que, de acordo com Souza (2005):

[...] ratificam a discriminação e a seletividade impostas pelo contexto social mais amplo. Logo, na maioria das vezes a pressão, o medo, o controle e o poder, ditados e expressos nas práticas avaliativas, retratam os mecanismos de uma sociedade que atua com princípios excludentes, de desigualdade e antidemocráticos. (p. 07).

A inclusão é uma temática recorrente em termos mundiais, que questiona as práticas anteriormente descritas e tem como principal cerne a consideração de todos os seres humanos com seus potenciais e características reconhecidas e plenamente valorizadas de maneira equitativa.

Nesse sentido, apresenta-se uma penosa situação para a escola que, sobretudo nas últimas décadas, passa a ser responsável por incluir todos os estudantes, oferecendo educação de qualidade comum, onde as diferenças e necessidades sejam igualmente respeitadas (Martins, 2006).

Diante dessa complexidade, pretende-se com este trabalho refletir sobre a avaliação da aprendizagem escolar como meio de inclusão em torno de duas importantes questões: Como analisar a inclusão se não partir da reflexão sobre a sua lógica contrária, a exclusão? Como avaliar para a inclusão, considerando as diferenças, sem relativizá-las ou centrá-las apenas nas limitações físicas, intelectuais, mentais ou sociais?

Para a reflexão das problemáticas apresentadas, aportamo-nos na perspectiva teórica crítica, por acreditarmos ser a que apresenta as proposições mais adequadas, na medida em que compreende que os seres humanos estão inseridos em um contexto social, histórico e cultural amplo, permeado por contradições. Dessa forma, não há como refletir sobre a escola, na qual nem todos os seus integrantes são capazes de se apropriarem dos conhecimentos por ela ensinados e produzidos, sem levar em consideração tais contradições.

Por isso, propugnamos a Teoria Histórico-Cultural iniciada por Lev Semenovitch Vygotsky $(1896$ - 1934) e seus colaboradores, para procedermos à análise de uma avaliação que contribua para a inclusão.

Embasada nos princípios filosóficos e metodológicos do marxismo, essa teoria se ocupa de compreender a realidade humana e fornecer subsídios para que os indivíduos se apropriem de meios para transformá-la. Nesse contexto, a mediação social tem um caráter fundamental, uma vez que o desenvolvimento do psiquismo é sócio-histórico (Meira, 2007).

Dentre os princípios do marxismo, destacamos o que aponta Saviani (2003), para quem o homem se diferencia dos outros animais pelo trabalho, isto é, pela capacidade de transformar a natureza para a garantia da sua existência. A apropriação do saber insere-se no contexto do trabalho não material, o que, a partir da apropriação das "ideias, conceitos, valores, símbolos, hábitos, atitudes, habilidades", torna os indivíduos históricos (p. 12).

Outro importante princípio é o movimento das contradições decorrentes da propriedade privada e da divisão social do trabalho, o que resulta na alienação provocada pela exploração das forças produtivas de trabalhadores por aqueles que detêm os meios de produção. Dessa estrutura social surgem contradições que podem ser superadas pelos 
indivíduos por meio da apropriação de sua própria produção material e espiritual (Duarte, 2011).

No interior da escola, essa estrutura social encontra eco na transmissão do conhecimento sem significação social para o aluno, que vive um processo de assimilação acrítico; por meio da reprodução, não se apropria desses conhecimentos para superação da alienação.

Barroco (2011) afirma que a defesa de Marx e Engels, desde o século XIX, valoriza a educação escolar como forma de consolidação da educação social, prima pela gratuidade e pela intrínseca relação entre educação e trabalho produtivo, de onde se observa a politecnia como "concepção de educação histórico-social" (p. 181). Esses princípios fundam uma nova concepção de sociedade calcada na coletividade para a estruturação de um sistema social organizativo que una o ensino ao trabalho social-produtivo.

Assim, a escola se apresenta como uma instituição fundamental para a promoção dos indivíduos singulares e para a sua inserção no mundo genérico, em que estes produzem e são produzidos, através da transmissão e da assimilação do saber sistematizado, considerado na história e de forma crítica, tornando-se a educação, portanto, um direito de todos os indivíduos. No entanto, contraditoriamente, a sociedade tem negado a muitos o usufruto pleno da educação escolar, o que fica conhecido no meio educacional como exclusão.

Sobre a proposta de educação e de sociedade inclusivas, Barroco (2007) enfatiza que a lógica da exclusão coincide com a lógica do capital na sociedade de classes, na qual uma pequena parcela de seus partícipes é incluída para a "apropriação, fruição e usufruto", enquanto outros lutam para sobreviver (p. 259).

A lógica estabelecida pelo capital conduz as pessoas a pensarem e agirem individualmente, a acumularem bens e conhecimentos que servirão para a conquista da sua liberdade, o que nega a condição sócio-histórica do homem e da sociedade que a escola precisa formar.

\section{A dialética entre a inclusão e a exclusão}

Para a compreensão dos caminhos da inclusão no contexto escolar, é necessária a percepção de que o seu surgimento manifesta-se em decorrência do seu contrário. O mister da implantação de políticas inclusivas dá-se pela presença da exclusão, cujas manifestações caracterizam-se por práticas discriminatórias ao diferente, ou seja, aqueles que não possuem aparentemente o potencial produtivo que garanta a sua existência imediata.

Essa lógica reflete nas escolas que arregimentam diversos profissionais para fornecer auxílio na solução dos problemas de aprendizagem e disciplina dos seus alunos. Dentre estes profissionais, estão professores, psicólogos, fonoaudiólogos e outros terapeutas de formações diversas, que tendem a aplicar tratamento individualizado, sob o ensejo da culpabilização ou direcionamento do foco para o que falta aos indivíduos e não às suas potências.
Cabe lembrar que tais profissionais são formados com base em concepções geradoras de simbolizações construídas social e historicamente direcionadas aos alunos com diferenças significativas, a exemplo das deficiências.

Essas concepções podem ser compreendidas pelos paradigmas da educação especial, conforme se descreve a seguir com embasamento nos estudos de Aranha (2004).

Inicialmente a deficiência foi considerada possessão demoníaca, e as pessoas com essa característica, no período da inquisição, eram julgadas pela igreja como a personificação do mal e, portanto, passíveis de castigos, torturas e mesmo de morte. Posteriormente, com os avanços da medicina, a deficiência passou a ser vista como doença, resultando nas primeiras práticas de atenção às pessoas com deficiência, traduzidas através do paradigma da institucionalização, que consiste em segregá-las em espaços institucionalizados para cuidado e proteção. A essa prática denominou-se Paradigma da Institucionalização, cujo apogeu, embora tenha vigorado até meados da década de 50 do século $X X$, reflete na educação e na sociedade até os dias atuais.

Tada (2009) afirma que esse paradigma é reforçado pela (ainda frequente) prática de identificação de "problemas dos alunos" através dos diagnósticos e testes psicométricos. Algumas escolas solicitam laudos médicos para a garantia do ingresso e permanência de alunos em seus quadros discentes sob o pretexto de assegurar melhores possibilidades de acompanhamento pedagógico. Essas práticas fortalecem ainda mais os processos de exclusão, considerando que, em alguns casos, os alunos apresentam desconhecimento prévio em relação às questões dos testes, o que é interpretado equivocadamente como inteligência insuficiente ou deficiência mental. Ações dessa natureza se apresentam inadequadas devido às sérias consequências resultantes dos rótulos de incapazes atribuídos aos alunos submetidos aos testes, gerando uma relação entre estes e seus professores prioritariamente mediada pela deficiência. "Institucionalizar uma pessoa pode trazer sérias consequências para o seu desenvolvimento, porque ela conviverá apenas com seus pares com deficiência e geralmente dentro de uma rotina pouco desafiadora" (p. 63).

O Paradigma dos Serviços foi o segundo modelo surgido para atenção às minorias. Como resultado de intensos movimentos sociais no mundo ocidental e influenciados pelas Grandes Guerras Mundiais, os países integrantes da Organização das Nações Unidas elaboraram, em 1948, a Declaração Universal dos Direitos Humanos, documento que, desde então, tem norteado os movimentos de definição de políticas públicas com vistas à integração, ou à reintegração na vida da comunidade. Nas décadas de 60 e 70, os países signatários da Declaração buscaram um novo modelo no trato da deficiência, tendo como princípio a normalização, que pode ser traduzida como capacitação para a convivência social (Aranha, 2004).

É evidente o quanto as crenças de que as pessoas com deficiência precisam ser institucionalizadas ainda persistem tanto na escola, quanto na sociedade. Um exemplo 
vigente é o fato de famílias de alunos e professores acreditarem que essa é uma responsabilidade da educação especial.

O terceiro e mais recente paradigma da educação especial é o Paradigma de Suportes, que surgiu em decorrência dos avanços tecnológicos e diminuição das barreiras geográficas, na perspectiva de propiciar maior qualidade de vida para todas as pessoas e, sobretudo, associando a ideia da diversidade como fator de enriquecimento social e o respeito às necessidades de todos os cidadãos como pilar central de uma nova prática social: a construção de espaços inclusivos (Aranha, 2004).

O movimento histórico do qual abrolham os paradigmas refletem no interior da educação escolar, reafirmando a questão da marginalidade impeditiva de avanços individuais e coletivos. Saviani (2000) amplia a discussão sobre a educação escolar em torno de dois grupos de tendências pedagógicas que perpetuam essa influência cotidianamente nas instituições escolares.

No primeiro grupo estão localizadas as teorias não críticas (tradicional, escola nova e tecnicista), que interpretam a educação como entidade autônoma capaz de promover por si mesma as mudanças sociais para a manutenção da harmonia, igualdade, coesão e equalização dos indivíduos que a constituem. O diferente é marginalizado por ser reconhecido como distorção que, por meio da escola, será corrigida.

No segundo grupo estão as teorias crítico-reprodutivistas (a escola como sistema de violência simbólica, a escola como aparelho ideológico de estado e a escola dualista), que interpretam a escola como reprodutora dos interesses dominantes da sociedade e, portanto, impotente para a superação dos conflitos que a sociedade apresenta. Nessa tendência, a marginalidade é vista como inerente à dinâmica social, e os integrantes do sistema escolar, apesar de entenderem a educação a partir dos seus condicionantes sociais, não são capazes de transformar essa mesma sociedade pela falta de consciência da situação em que se encontram.

A reflexão que se coloca é a de que os caminhos a se trilhar ainda são extensos, considerando que as formas de interpretar o mundo foram solidificadas no decorrer do tempo na sociedade ocidental que primou pelos ideais liberais, advindos do pensamento burguês, com o objetivo de romper com o modelo feudal baseado em uma hierarquia universal. Como elemento central, adota-se uma visão de homem individual, cujo "individualismo" inerente é calcado nos princípios da liberdade, igualdade e fraternidade, gerando a noção de vida privada (Bock, 2009).

A noção de vida privada, advinda do capitalismo e basilada nas ideias individualistas, pressupõe que cada ser é único, detentor de seus pensamentos e proprietário de seus bens, a meritocracia passa a fundamentar as suas ações em uma sociedade que oferece direitos iguais. Contudo, as oportunidades e o usufruto dos bens produzidos não correspondem às necessidades de todos os indivíduos, gerando a organização da sociedade em classes com interesses antagônicos.

Os campos da igualdade são os mesmos que delimitam as diferenças, uma vez que se espera um comportamento "igual" de seres que apresentam peculiaridades, idiossincrasias, singularidades, subjetividades que a escola não tem conseguido administrar com seus padrões representados por classes homogêneas, currículos estanques e, sobretudo, com um sistema de avaliação composto a partir da medição de conhecimentos nivelados e da atribuição de notas na forma de medidas padronizadas.

Essa não é uma temática que envolve apenas os alunos com deficiência, pois as diferenças apresentadas por indivíduos nas salas de aula são inúmeras e perpassam por questões econômicas, sociais, culturais, afetivas, biológicas, religiosas, étnicas, geradoras de discriminação preconceito e estigmatização.

Velho e cols. (1985) apontam a estigmatização das crianças como forma de atribuição de rótulos, ocasionando graves consequências que se prolongam pela vida adulta, impedindo-as de viver dignamente em sociedade, por serem consideradas desviantes.

Segundo os autores, são as relações sociais que determinam o padrão desviante, não sendo esse padrão constitutivo de apenas um indivíduo. A condição de desviante pode ser compreendida tanto pela concepção que se tem acerca do aluno com deficiência quanto àqueles que apresentam superdotação/altas habilidades ou outras diferenças.

Considerando que dos processos de aprendizagem decorrem o desenvolvimento biológico e social, na formação da consciência dos indivíduos, a escola ocupa um lugar privilegiado. Para Vygotsky (1995), os planos natural e cultural, representados por fatores biológicos e sociais, estão em constante relação. As mudanças ocorridas em ambos os planos definem-se historicamente, pois o desenvolvimento biológico e o cultural ocorrem simultaneamente e exercem constante influência um sobre o outro.

Destarte, é possível afirmar que educar é adentrar na diversidade. É agir deliberadamente em favor do reconhecimento de que não existem pessoas iguais e de que a formação cultural depende de fatores que vão além das características físicas ou da simples predisposição biológica.

A avaliação da aprendizagem escolar apresenta-se como elemento importante para o enfrentamento das dificuldades inerentes ao processo de aprendizagem e desenvolvimento dos alunos, pois se encontra no cerne da atividade educativa escolar, fazendo assim um par dialético com a inclusão.

\section{A avaliação escolar e suas premissas}

De acordo com Hoffmann (2001), a avaliação da aprendizagem escolar deve afastar-se das "verdades absolutas, dos critérios objetivos, das medidas padronizadas e das estatísticas" para inserir em seu contexto a reflexão acerca dos objetivos a serem alcançados, o que deve necessariamente envolver diálogo entre professores e alunos (p. 18).

A autora afirma que os atuais estudos sobre a temática da avaliação escolar apontam para uma postura mais abrangente daquela avaliação que, embasada em ideias positivistas, reforçava o caráter classificatório e traçam um 
paralelo entre as polêmicas presentes entre as alternativas de progressão continuada e as práticas seletivas e excludentes.

O que se denomina frequentemente por avaliação são apenas instrumentos utilizados para a sua objetivação. A avaliação deve ser identificada como processo e não como um fim, utilizada unicamente para detectar quantitativamente o que o aluno memorizou. Uma avaliação realizada apenas em etapas estanques da formação dos alunos desconsidera o caráter processual, portanto histórico, da apropriação dos conceitos e nega a historicidade humana, o que resulta em exclusão, que traduzimos neste trabalho como marginalização.

O principal esforço dos educadores e demais envolvidos no processo educativo tem sido mais relacionado à definição de critérios e registros utilizados para o fornecimento de resultados finais, consignados em notas, com o intento de atender aos trâmites burocráticos, em detrimento dos avanços individuais dos alunos, observados qualitativamente.

As contradições inerentes aos processos avaliativos se apresentam pela oposição entre os ideais liberais do capitalismo e uma visão de avaliação libertadora. A primeira defende a competição, a individualidade e a reprodução da organização social vigente, enquanto a segunda visa ao desenvolvimento de consciência crítica para a superação da dominação através de reflexões sobre as desigualdades sociais (Hoffmann, 1993).

Por esta forma, a avaliação não pode ser pensada apenas na perspectiva da normalidade versus anormalidade como algo naturalizado. As diferenças sociais nos conduzem a aprofundar a questão educacional, considerando as especificidades que se apresentam, dentre estas as deficiências, as dificuldades de aprendizagem e outros fatores limitadores, mas não impeditivos de aprendizagem.

Pensar a inclusão é ir além das deficiências e limitações para a superação da realidade da exclusão atualmente imposta, na qual os estudantes são colocados à margem da escola pela negação do acesso ao saber sistematizado, à permanência na escola e à saída com o domínio de um conhecimento que lhes favoreça o real exercício da cidadania.

Afirma Luckesi (2008) que, numa visão liberal de avaliação, em geral "a prática pedagógica está polarizada pelas provas e exames", para os quais as atenções são fortemente vinculadas no sentido da coação e afirmação de poder ou ainda do estabelecimento de expectativas de promoção e não nos processos de aprendizagem (p. 18).

Lembrando Asbahr (2007), os indivíduos representam suas significações por meio de incorporação e apropriação das relações sociais, o que direciona os motivos para a sua atividade, ou seja, o sentido pessoal é para o sujeito o reflexo das mediações promovidas socialmente. O sentido pessoal não corresponde às significações sociais, pois depende das experiências de cada sujeito em relação à sua história como ser singular. Cabe enfatizar que as significações partilhadas coletivamente é que determinarão o significado para a atividade social.

Nesse sentido, cabe refletirmos com Saviani (2003) o papel da escola, para quem:
O trabalho educativo é o ato de produzir, direta e intencionalmente, em cada indivíduo singular, a humanidade que é produzida histórica e coletivamente pelo conjunto dos homens. Assim, o objeto da educação diz respeito, de um lado, à identificação de elementos que precisam ser assimilados pelos indivíduos da espécie humana para que eles se tornem humanos e, de outro lado e concomitantemente, à descoberta das formas mais adequadas para atingir esse objetivo (p. 13).

Nessa visão, a humanização dos indivíduos constitui-se através das relações materiais e sociais e são consequentemente transpostas para o âmbito escolar. Para que a escola cumpra o papel de contribuir para que indivíduos se tornem humanos, o autor propõe uma Pedagogia que busca apreender a educação "com base no desenvolvimento histórico-objetivo", denominada Pedagogia Histórico-Crítica (p. 88).

Para Vigotsky (citado por Pino, 2005), o cerne da questão educativa deverá ser o desenvolvimento das formas superiores de conduta, reguladas pelo aspecto cultural, cujo conceito é "simultaneamente, o produto da vida social e da atividade social dos homens" (p. 18).

Sobre as formas superiores de conduta, Vygotsky (1995) afirma que são dois fenômenos relacionados entre si: o primeiro envolve a apropriação dos meios externos de desenvolvimento cultural do pensamento, isto é, de tudo que foi criado pelo mundo da cultura por meio da transmissão do saber ("a linguagem, a escrita, a aritmética, o desenho"). O segundo diz respeito às "funções psíquicas superiores especiais" que envolvem a "atenção voluntária, memória lógica, formação de conceitos etc.". Embora heterogêneos, esses dois fenômenos são indissociáveis entre si, mas não se fundem (p. 29).

Nesse sentido, defendemos a avaliação da aprendizagem como ação que, se aplicada e interpretada adequadamente, favorecerá o aluno no seu desenvolvimento educativo, por possibilitar a identificação das progressões, sintetizadas neste trabalho como meio para inclusão de todos os estudantes independentemente das suas diferenças.

É necessário reconhecer quais serão as vias utilizadas para a identificação do desempenho do estudante em uma condição processual, ressaltando que o interesse dos educadores deverá estar voltado ao desempenho individual dos estudantes, considerando a situação real de aprendizagem para a definição das estratégias que serão utilizadas para a realização da avaliação.

Em uma proposta de escola inclusiva, destacamos que o ser que avalia não é neutro e que, dependendo do significado que atribui para a estruturação da sua interpretação de mundo, de sociedade e de existência, a avaliação configurar-se-á como um problema ou como perspectiva de fundação de uma escola que irá efetivamente incluir.

Hoffmann (2001), defendendo a avaliação como uma ação mediadora entre o aluno e o conhecimento, define como princípio, primeiro, que a avaliação deve estar a serviço da ação, o que exige uma ação pedagógica reflexiva e crítica. 
Para a autora, a avaliação mediadora confronta objetivos pretendidos e alcançados. Ressalta o apoio do planejamento para que educadores/avaliadores acompanhem e compreendam as progressões dos seus alunos e possam promover ações eficazes.

Sobre comportamentos e formas de acompanhamento, Hoffmann (2001) sinaliza para a essencialidade da tomada de consciência do professor sobre o significado dos registros $^{1}$ em avaliação como forma de concretude e dinamismo de uma história construída. "O que se diz sobre o aluno é o que se construiu com ele, e revela o que se fez e se deixou de fazer para favorecê-lo em termos de sua experiência educativa" (p. 207).

A mudança de consciência é transversalizada pelo que Marx e Engels asseveram em A ideologia alemã (1991): "a verdadeira riqueza espiritual dos indivíduos passa pelas suas relações reais" (p. 54). Em um processo educativo dissociado da história, de seus movimentos, contradições e bases materiais, a superação consciente da avaliação excludente torna-se inviável.

Nesse sentido, a superação das formas de exclusão vivenciadas atualmente pelo sistema educativo escolar dependerá de profundas reflexões acerca da dialética entre a avaliação com moldes aportados na classificação e seleção, que referendam a exclusão, para uma avaliação que promova a inclusão de todos os estudantes com ou sem deficiência.

Para tanto, é necessário o reconhecimento de que a educação é um direito de todos, conquistado historicamente e fundado em lutas e contradições, para a garantia do usufruto digno a todas as pessoas dos bens materiais e espirituais, consolidados pela humanidade no movimento da história.

\section{Conclusão}

A avaliação é um processo constitutivo do ato educativo, é ação política que deve ser construída coletivamente na intenção de formar cidadãos conscientes de seu papel em uma sociedade diversa.

Portanto, a avaliação não demonstrará seus resultados de outra maneira senão a partir da compreensão das relações estabelecidas entre os atores sociais, dentre os quais estão os estudantes, com características físicas, sociais ou intelectuais diferenciadas, professores e demais integrantes da comunidade escolar. Isso envolve o reconhecimento da realidade como esta se apresenta, considerando as suas contradições, fundadas em bases materiais determinantes tanto da exclusão, quanto da sua superação, ou seja, o caminho da inclusão.

Da mesma forma que as pessoas apresentam características diferentes, igualmente diferentes serão suas escolhas, formas de expressão, percepções, abstrações e interpretações a respeito da realidade. Isso resulta na ne-

1 A autora sugere a adoção de registros na forma de dossiês, portfólios e relatórios de avaliação para favorecer o acompanhamento dos processos individuais de aprendizagem dos alunos. (p. 200) cessidade do reconhecimento, pelos educadores, de que não existe uma única possibilidade ou um momento certo para avaliar os seus alunos que se encontram em constante movimento na busca por se firmarem como seres singulares, autônomos e reguladores de sua própria conduta, apesar das diferenças.

Entretanto, se faz necessário que a visão que se tem dos estudantes seja direcionada para o contexto social em que eles estão inseridos, isto é, uma sociedade contraditória e muitas vezes excludente que pretere potencialidades humanas e se configura em classes, desconsiderando que, para se fundar o coletivo, é fundamental considerar as singularidades.

Assim, a escola deve preparar indivíduos capazes de avaliar suas ações, generalizar conhecimentos e experiências, fazer análises e sínteses, que tenham desenvolvidas as suas funções superiores por meio da aprendizagem escolar, considerando não apenas a dimensão individual, mas, sobretudo, a dimensão coletiva.

Para tanto, a educação necessita de mais estudos em vertentes críticas que analisem a educação escolar como possibilidade de desenvolvimento do homem que vive na história ao passo que a constrói.

No campo da Psicologia, uma possibilidade é estudar a inclusão, na vertente da Teoria Histórico-Cultural, considerando os determinantes sociais como fatores de exclusão. Os processos de aprendizagem e desenvolvimento dos alunos devem ser mediados pelas potências que eles possuem e não por aquilo que lhes falta, afastando os fatores de culpabilização individuais, que atualmente ora são direcionados aos próprios educandos e às suas famílias e ora aos educadores.

No âmbito da educação escolar, a Pedagogia Histórico-Crítica pode fornecer subsídios para a interpretação da função social da escola e a definição de práticas críticas de avaliação.

Para uma avaliação da aprendizagem escolar a serviço da inclusão, é preciso ultrapassar os instrumentos descontextualizados e as etapas dissociadas da história e de seu caráter processual, para a compreensão da sociedade e dos seus reflexos como contradições que precisam ser superadas.

\section{Referências}

Aranha, M. S. F. (2004). Educação inclusiva: a fundamentação filosófica. Brasília, DF: Secretaria de Educação Especial.

Asbahr, F., \& Souza, M. P. R. (2007). Buscando compreender as políticas públicas em educação: contribuições da Psicologia Escolar e da Psicologia Histórico-Cultural. Em M. G. D. Facci \& M. E. M. Meira (Orgs.), Psicologia Histórico-Cultural: contribuições para o encontro entre a subjetividade e a educação (pp. 185-220). São Paulo: Casa do Psicólogo. 
Barroco, S. M. S. (2007). Psicologia e educação: da inclusão e exclusão ou da exceção e da regra. Em M. G. D. Facci \& M. E. M. Meira (Orgs.), Psicologia Histórico-Cultural: contribuições para o encontro entre a subjetividade e a educação (pp. 157-184). São Paulo: Casa do Psicólogo.

Barroco, S. M. S. (2011). Pedagogia histórico-crítica, psicologia histórico-cultural e educação especial: em defesa do desenvolvimento da pessoa com e sem deficiência. Em A. C. G. Marsiglia (Org.), Pedagogia histórico-crítica: 30 anos (pp. 170196). Campinas, SP: Autores Associados.

Bock, A. M. B. (2009). A Psicologia sócio-histórica: uma perspectiva em psicologia. Em A. M. B. Bock, M. G. M. Gonçalves \& O. Furtado (Orgs.), Psicologia sócio-histórica: uma perspectiva em psicologia (4a ed.). São Paulo: Cortez.

Duarte, N. (2011). Fundamentos da Pedagogia Histórico-Crítica: a formação do ser humano na sociedade comunista como referência para a educação contemporânea. Em A. C. G. Marsiglia (Org.), Pedagogia histórico-crítica: 30 anos (pp. 7-21). Campinas, SP: Autores Associados.

Hoffmann, J. M. L. (1993). Avaliação mediadora: uma prática em construção da pré-escola à universidade. Porto Alegre: Educação \& Realidade.

Hoffmann, J. M. L. (2001). Avaliar para promover: as setas do caminho. Porto Alegre: Mediação.

Luckesi. C. C. (2008). Avaliação da aprendizagem escolar: estudos e proposições (14a ed.). São Paulo: Cortez.

Luckesi. C. C. (2011). Avaliação da aprendizagem: componente do ato pedagógico. São Paulo: Cortez.

Martins, L. A. R. (2006). Inclusão escolar: algumas notas introdutórias. Em L. A. R. Martins, F. R. L. V. Melo, G. N. L. Pires \& J. Pires (Orgs.), Inclusão: compartilhando saberes (pp. 17-26). Petrópolis, RJ: Vozes.
Marx, K., \& Engels, F. (1991). A ideologia alemã (Feuerbach) (8a ed.). São Paulo: Hucitec.

Meira, M. E. M. (2007). Psicologia Histórico-Cultural: fundamentos, pressupostos e articulações com a Psicologia da Educação. Em M. G. D. Facci \& M. E. M. Meira (Orgs.), Psicologia HistóricoCultural: contribuições para o encontro entre a subjetividade e a educação (pp. 27-62). São Paulo: Casa do Psicólogo.

Pino, A. (2005). Cultura e desenvolvimento humano. Em Coleção Memória da Pedagogia, Edição Especial n. 02, Lev Semenovich Vygotsky: uma educação dialética (pp. 14-21). Rio de Janeiro: Ediouro; São Paulo: Segmento-Duetto.

Saviani, D. (2000). Escola e democracia: teorias da educação, curvatura da vara, onze teses sobre a educação política (33a ed.). Campinas, SP: Autores Associados.

Saviani, D. (2003). Pedagogia histórico-crítica: primeiras aproximações (8a ed.). Campinas, SP: Autores Associados.

Souza, A. M. L. (2005). Avaliação de aprendizagem no ensino superior na perspectiva do aluno. Tese de doutorado, Universidade de São Paulo, São Paulo.

Tada, I. N. C. (2009). Os desafios de atuação do psicólogo escolar: da educação especial à educação inclusiva. Em A. M. L. Souza (Org.), Psicologia, saúde e educação: desafios na realidade amazônica (pp. 61-83). São Carlos, SP: Pedro e João Editores; Porto Velho: Edufro.

Velho, G. (Org.). (1985). Desvio e divergência: uma crítica da patologia social (5a ed.). Rio de Janeiro: Jorge Zahar,

Vygotsky, L. S. (1995). Obras Escogidas III: problemas del desarrollo de la psique. Madrid: Visor Distribuciones.
Recebido em: 04/10/2011

Reformulado em: 15/02/2012

Aprovado em: 24/02/2012 
Sobre as autoras

Ana Maria de Lima Souza (ana26souza@hotmail.com)

Graduada em Pedagogia pela Universidade Federal do Pará (1978), mestre (2000) e doutora (2005) em Psicologia Escolar e do Desenvolvimento Humano pelo Instituto de Psicologia da Universidade de São Paulo. Professor Associado no Departamento de Ciências da Educação e do Mestrado Acadêmico em Psicologia da Fundação Universidade Federal de Rondônia - UNIR; membro do Centro de Pesquisa em Formação da Pessoa - CEPEFOP, Rondônia, Brasil. Endereço: Rua Quintino Bocaiúva, 2552 - Bairro São Cristóvão. Porto Velho, RO - Brasil - CEP 76 804-008.

Marasella del Cármen Silva Rodrigues Macedo (marasella@gmail.com)

Graduada em Pedagogia e mestranda do Mestrado Acadêmico em Psicologia - MAPSI pela Universidade Federal de Rondônia - UNIR; membro do Centro de Pesquisa em Formação da Pessoa 